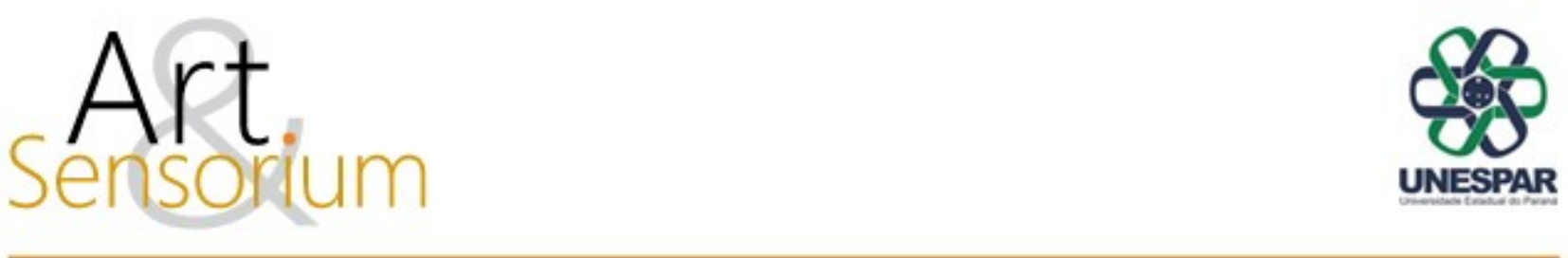

\title{
O TAPETE DE VIDRO NA SALA DE ESTAR: UMA ESCULTURA PERCORRÍVEL EM CURITIBA
}

DOI: https://doi.org/10.33871/23580437.2021.8.2.081-092

\author{
Renan Battisti Archer ${ }^{1}$ \\ Artur Freitas $^{2}$
}

\begin{abstract}
RESUMO: A obra "Ladrilhos", da artista Laura Miranda, consiste numa obra de arte site-specific instalada em 1992 em espaço público, na cidade de Curitiba, que faz parte da paisagem urbana. Este artigo realiza uma análise deste trabalho artístico, no intuito de revelar seu processo de produção e como este cria especificidades a partir do fato de sua instalação em ambiente urbano. A princípio, utiliza-se o conceito de espaço em obra de Alberto Tassinari (2001) para compreender a relação física da escultura com seu entorno. Já para entender como o espaço participa subjetivamente da obra em seus aspectos históricos e sociais, a noção de functional site de James Meyer (2000) é pertinente, bem como o levantamento de dados sobre o histórico do desenvolvimento urbano da cidade de Curitiba, em particular da Rua XV de Novembro. Com este trabalho, procura-se realizar uma análise de como a obra de arte em questão assume particularidades materiais e conceituais pela sua condição de existência pública. Visa-se também realizar um debate conceitual sobre os limites físicos e poéticos testados pela arte quando instala-se na cidade, utilizando a obra analisada como um estudo de caso. Por fim, confirma-se a conexão intrínseca entre a escultura "Ladrilhos" e os aspectos políticos e sociais de seu contexto, enquanto a obra é lida a partir de uma subjetividade que revela facetas inéditas do espaço em que se insere.
\end{abstract}

Palavras-chave: Site-specific; Laura Miranda; arte pública; Curitiba; escultura.

\section{THE GLASS CARPET IN THE LIVING ROOM: A WALKABLE SCULPTURE IN CURITIBA}

\begin{abstract}
Ladrilhos", by artist Laura Miranda, consists of a site-specific artwork installed in 1992 in a public space, in the city of Curitiba, existing as part of the urban landscape. This paper analyzes this artwork in order to reveal its creation process and how it creates specificities based on

\footnotetext{
${ }^{1}$ Universidade Federal do Paraná. Mestrando em História (Arte, Memória e Narrativa) pela Universidade Federal do Paraná, graduado em Artes Visuais pela mesma instituição. Tem afinidade com a pesquisa em história, crítica e teoria da arte, com foco para as manifestações de arte pública contemporânea. Atua enquanto curador independente, redator para projetos culturais e jornalista cultural. Curitiba, Paraná, Brasil. $\quad$ Lattes: http://lattes.cnpq.br/5885649823036599. ORCID: https://orcid.org/0000-0002-5545-0709 E-mail: renan.archer@gmail.com

2 Professor Associado de História da Arte do curso de Artes Visuais e do Programa de Pós-Graduação em Artes da Universidade Estadual do Paraná (PPGARTES/UNESPAR), professor do Programa de Pós-Graduação em História da Universidade Federal do Paraná (PPGHIS/UFPR), líder do Grupo de Pesquisa Núcleo de Artes Visuais (NAVIS/CNPq) e autor, entre outros, de Arte de Guerrilha (Edusp, 2013), Festa no Vazio (Intermeios, 2017), Arte e Contestação (Curitiba: Medusa, 2013) e Arte e Politica no Brasil (Org. Perspectiva, 2014). Lattes: http://lattes.cnpq.br/7705592106667807 ORCID: https://orcid.org/0000-0003-3041-4725 E-mail: artur.imagem@gmail.com
} 
the fact that it is installed in an urban environment. At first, the concept of space in work by Alberto Tassinari (2001) is used to understand the physical relationship between the sculpture and its surroundings. To understand how the space subjectively participates in the work in its historical and social aspects, James Meyer's (2000) notion of functional site is pertinent, as well as the research on the history of urban development in the city of Curitiba, in particular the Novembro XV Street. With this paper, the objective is to carry out an analysis of how the artwork in question takes on material and conceptual particularities due to its condition of a public object. It is also intended to carry out a conceptual debate on the physical and poetic limits tested by art when it settles in the city, using the analyzed artwork as a case study. Finally, the intrinsic connection between the sculpture "Ladrilhos" and the political and social aspects of its context is confirmed, while the artwork is read from a subjectivity that reveals unprecedented facets of the space in which it is inserted.

Keywords: Site-specific; Laura Miranda; public art; Curitiba; Sculpture.

\section{LA ESTERA DE VIDRIO EN LA SALA DE ESTAR: UNA ESCULTURA VIAJABLE EN CURITIBA}

RESUMEN: La obra "Ladrilhos", de la artista Laura Miranda, consiste en una obra de arte site-specific instalada en 1992 en espacio público, en la ciudad de Curitiba, que forma parte del paisaje urbano. Este artículo realiza un análisis de este trabajo artístico, con el intuito de evidenciar su proceso de producción y las particularidades derivadas de su instalación en un ambiente urbano. En un principio, el concepto de espacio en la obra de Alberto Tassinari (2001) es utilizado para entender la relación física de la escultura con su entorno. Para poder entender como el espacio participa subjetivamente de la obra en sus aspectos históricos y sociales, la noción de functional site de James Meyer (2000) es pertinente, así como el levante de datos sobre el historial del desarrollo urbano de la ciudad de Curitiba, en particular de la calle XV de Novembro. Este trabajo busca realizar un análisis de cómo esta obra de arte asume particularidades materiales y conceptuales por su condición de existencia pública. Así como realizar un debate conceptual respecto de los límites físicos y poéticos puestos a prueba por el arte cuando esta se instala en la ciudad, utilizando la obra analizada como un estudio de caso. Finalmente, se confirma la conexión intrínseca entre la escultura "Ladrilhos" y los aspectos políticos y sociales de su contexto, a medida en que la obra es interpretada a partir de una subjetividad que pone en evidencia facetas inéditas del espacio en el cual está inserida.

Palabras Clave: Site-specific; Laura Miranda; arte publico; Curitiba; escultura.

Em maio de 1992, a cidade de Curitiba recebeu um conjunto de obras de arte instaladas em espaços públicos como parte do Projeto Escultura Pública, iniciativa de seis artistas e a galeria de arte Casa da Imagem. "Ladrilhos" foi uma das obras, produzida por Laura Miranda, que encabeçou o Projeto na companhia de David Zugman, Denise Bandeira, Eliane Prolik, Marco A. Silveira Mello, Rossana Guimarães e Yiftah Peled. A intenção foi inserir a arte contemporânea em espaços públicos iniciando um debate sobre o relacionamento entre os viventes da urbe e a arte. A jornalista e crítica de arte paranaense Adalice Araújo, que acompanhou o projeto, resumiu bem os objetivos do coletivo:

Suprir a ausência de esculturas públicas em alguns espaços da cidade; renovar o olhar, abrindo-o à contemporaneidade; constituir estímulos que possibilitassem o desenvolvimento de uma consciência da importância da escultura pública; iniciar uma reflexão acerca da complexidade de questões que envolvem a instalação de esculturas nos espaços urbanos (ARAÚJO, 1992, p.7). 
Tudo isso se materializou na criação de obras site-specific, em que a materialidade foi trabalhada de forma a se relacionar com seus espaços em nível físico ou conceitual ${ }^{3}$. Tais obras sugerem uma prática artística a partir de uma percepção crítica dos aspectos objetivos e subjetivos dos espaços de realização. Em documento resultante do projeto (uma carta redigida ao prefeito de Curitiba em 1993), os integrantes defenderam a permanência das obras do Escultura Pública no espaço a partir da ideia de que "uma escultura no espaço público constitui uma zona especial e temporal particular (...) um sítio não regrado pelo mundo mecânico-industrial" e que "seu tempo ultrapassa a presentificação e é capaz de legar uma nova significação à vivência coletiva" (BANDEIRA et al., 1993). Desse modo, as obras não seriam apenas uma presença material impositiva, mas seriam absorvidas pelo cotidiano e seus viventes. O objetivo deste trabalho é entender de que forma essa integração com a cidade se deu a partir da obra produzida pela artista Laura Miranda, quais formas e relações produziu com o entorno e seus integrantes.

Este trabalho pretende analisar a obra "Ladrilhos" partindo do princípio que, enquanto intervenção urbana site-specific, seu sentido não esgota-se em suas qualidades formais, mas emergem do seu contexto. Assim, o intuito é entender o duplo diálogo que a obra produz: com históricos e conceitos da história da arte através de sua abordagem formal, bem como com seu entorno social. Para cumprir esses objetivos, em um primeiro momento será investigado o processo da fatura e visualidade da obra enquanto escultura contemporânea, sobretudo a partir da articulação com o conceito de "espaço moderno" de Alberto Tassinari (2001). Em um segundo momento, o foco passará para o contexto e o entorno ambiental da obra, entendendo como esta se articula com um local específico (neste caso, a cidade de Curitiba e a sua Rua XV de Novembro). Conceitos como o de functional site de James Meyer (2000) e as noções sobre arte pública e intervenção urbana de Peixoto (1999) serão úteis a essa análise. Ao longo deste trabalho, pretende-se verificar como a obra produz resultados específicos graças à sua natureza de intervenção urbana site-specific, bem como entender as dimensões artísticas desse fato.

\section{UMA ESCULTURA NA CALÇADA, UM ESPAÇO EM OBRA}

"A escultura é um protótipo, através dela a gente realiza um teste, verifica até que ponto as pessoas estão distantes dessas obras e qual é a aceitação" (MIRANDA, 1992). O relacionamento com o público na obra de Laura Miranda é resultado de escolhas formais pensadas para interagir com a visualidade do espaço e criar experiências que penetram no cotidiano urbano. É a única obra no Projeto Escultura Pública que resiste ainda parcialmente em sua paisagem original, instalada no famoso "calçadão" da Rua XV de Novembro, no centro da cidade de Curitiba.

Cerca de 480 ladrilhos de vidro soprado formavam o corpo da obra. Transparentes e com pequenas ranhuras, seu formato intencionalmente aproximava-se ao reconhecido componente basilar da Rua $\mathrm{XV}$ de Novembro em Curitiba, o petit-pavé. A artista removeu pedras originais, inserindo as de vidro em seu lugar, com as quais criou um retângulo que media aproximadamente $100 \times 500 \mathrm{~cm}$, situado no mesmo nível da rua. A obra funciona como uma espécie de continuação do próprio "calçadão" original, mesclando-se na paisagem urbana. Não se trata de um objeto que apenas se apresenta e confia na sua autonomia visual para encontrar seu sentido. Faz isso, na verdade, se estendendo ao espaço e produzindo uma relação de dependência com o entorno.

\footnotetext{
${ }^{3}$ Para os artistas do projeto, isso aconteceu em diferentes níveis. Eliane Prolik, por exemplo, produziu pesadas esculturas geométricas distribuídas sobre calçadas, enquanto Yiftah Peled, outro artista, realizou performances públicas e intervenções efêmeras em vários locais.
} 




Figura 1. "Ladrilhos", de Laura Miranda, sendo instalada. Foto: Laura Miranda. Fonte: SGODA, 2013.

Na Rua XV de Novembro, a obra se estende enquanto uma coisa única formada entre centenas de pedaços menores, se unindo ao que ali já estava antes dela chegar. Os pequenos quadrados sólidos e transparentes criam juntos um equilíbrio que não esconde a tensão entre a regularidade das peças de vidro e a irregularidade do petit-pavé. Pode ser vivenciada - ou simplesmente apreciada - público a partir de qualquer ângulo, pois não há hierarquia entre suas partes. À primeira vista, podem ser percebidas algumas aproximações entre a solução visual da obra com alguns preceitos do movimento heterogêneo minimalismo ${ }^{4}$, que teve suas primeiras experiências na década de 1960 com artistas como Robert Morris, Carl André e Donald Judd. A primeira semelhança é a dispensa de um aspecto composicional, sendo a obra formadas por vários componentes idênticos: a composição, para Judd (2006, p. 101) “minimiza o impacto da obra como um todo". Também no uso de materiais industriais ecoa a prática minimalista, uma solução que revela a "ausência do artista" com vias de "desfetichizar a obra de arte, abri-la à compreensão do público (...)" (FOSTER, 2015, p. 132). Contudo, a obra de Laura Miranda extrapola as intenções do minimalismo de que a arte é literal e não é nada mais do que mostra. A característica mais pertinente em "Ladrilhos" e que a diferencia do minimalismo, aproximando-ada contemporaneidade, é a exploração que faz do espaço urbano. A rua e seu "calçadão" não são apenas o contexto espacial, mas o ambiente que alimenta a obra de sentido: ela estende-se ao mundo comum, desdobra-se no cotidiano e atinge os passos daqueles que, possivelmente, nem perceberão que está lá, mas participarão da sua ativação.A partir do conceito de "espaço em obra" de Alberto Tassinari compreende-se como a obra vive em constante troca com seu entorno, com o real e sua casualidade, para além de uma proximidade com um movimento artístico

\footnotetext{
${ }^{4}$ Discutindo sua obra, Laura Miranda confirmou afinidades, sobretudo na colocação do espaço como parte de seu sentido (ESCULTURA Pública, 2012). Também o fez a pesquisadora Tânia Bloomfield (2012), lembrando a obra 144 Magnesium Square (1969) do artista minimalista Carl André.
} 
específico, inserindo-a num debate sobre a construção de um espaço próprio (que não é autônomo, ao menos não no sentido de "independência" formal em relação ao contexto social de instalação). É a arte em plena relação com o entorno, não como forma de embate ou negação, mas habitando-o e utilizando-o como componente. Para Tassinari, essa abordagem artística que produz relações tão próximas com o mundo compreende o "espaço moderno" em sua fase de "desdobramento" (TASSINARI, 2001, p.39), ou seja, inseridas numa esteira de práticas artísticas que a partir dos anos 1970 perdem seu "contorno" ou resquício de espacialidade imanente e expandem-se para um espaço mais amplo, de ordem vivencial, desafiando as delimitações materiais que antes pareciam subordinadas às intenções da pessoa artista. A partir dessa identificação, a obra existe sem um espaço fechado em si e unificado, o que não consiste numa perda de conteúdo, mas na transferência deste para o exterior. Num espaço em obra, barram-se então os limites entre o espaço da arte e aquele do cotidiano, já que "espaço do mundo em comum é que será seu complemento" (TASSINARI, 2001, p.44). Há um paralelo possível aqui com o conceito de "campo ampliado" de Rosalind Krauss (2008, p.135), lançado em artigo homônimo escrito em 1979 pela crítica de arte estadunidense, para denominar e classificar as interferências artísticas permanentes ou temporárias em paisagens, as obras de localização específica (site-specific), as instalações arquitetônicas em ambientes abertos e fechados, bem como suas possíveis combinações. Por sua vez, Hal Foster (2015, p.130) vai dizer que, de modo geral, são essas obras com tal relação espacial que "articulam os corpos e os objetos em espaços reais" e produzem experiências estéticas que transbordam os limites físicos do objeto, assumindo o tempo e o espaço do espectador.

"Ladrilhos" incorpora uma parcela da paisagem da cidade, seus fluxos e funções, que encontram-se conservados após a instalação da escultura, como uma obra que encontra seu lugar em meio às múltiplas imagens do dia a dia urbano. A obra não incorpora o espaço como se pedisse emprestado um registro espacial da realidade para encaixá-lo como componente extra, muito menos cria uma espécie de cerca espaço-temporal em que a obra apenas reflete o lugar em que se instala. Ao contrário, ela produz seu próprio espaço em obra, sendo que o ambiente em que se insere segue construindo a obra sem parar e por ela é construído, ao mesmo tempo que vive também as transformações constantes do cotidiano da cidade.

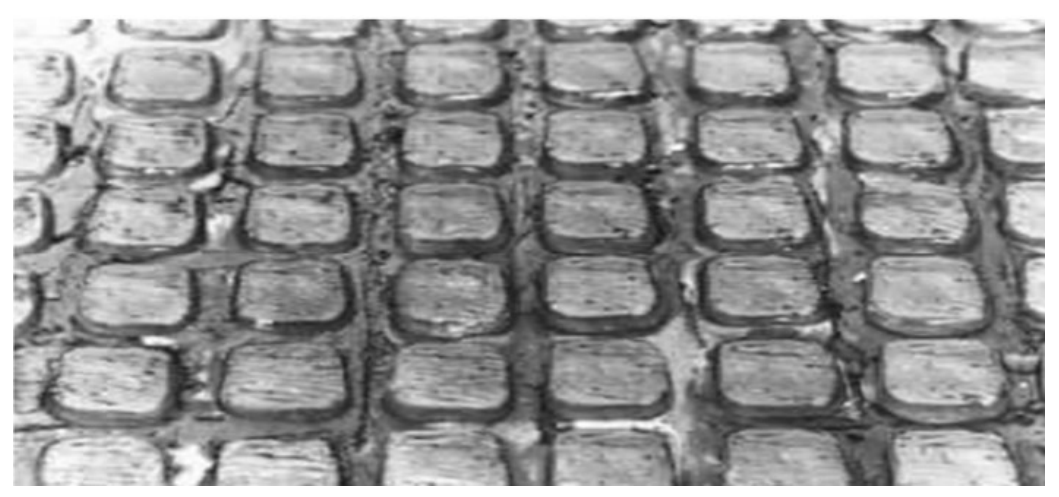

Figura 2. Detalhe da obra "Ladrilhos”, de Laura Miranda. Foto: autor não identificado. Fonte: SGODA, 2013.

A experiência de apreciação da obra passa pelo corpo anônimo do transeunte e o deslocamento que este faz pelo espaço da obra. Neste fluxo, os materiais utilizados têm grande importância, acumulando duas principais funções: primeiro, promover unidade entre todos os componentes da obra, um relevante aspecto formal que integra o trabalho ao espaço; segundo e mais importante, iniciar um fluxo de energias corporais que começa na fatura do trabalho e continua na vivência do espectador. $\mathrm{O}$ interesse da artista pelo vidro soprado veio por meio do processo que envolve e desperta o corpo: uma técnica que depende do ar dos pulmões, da atenção dos olhos, da habilidade das mãos (ESCULTURA Pública, 2012). Depois de sólidos, os pequenos tijolos transparentes conceberam uma obra que continuou (e continua) indefinidamente recebendo estímulos como parte 
de um organismo urbano incessante. A artista foi responsável por idealizar esse processo, mas não a única a executá-lo: os pequenos tijolos transparentes da obra de Laura Miranda tiveram produção terceirizada, ficando na responsabilidade de uma cristaleria contratada ${ }^{5}$. O espaço que esses ladrilhos ocupam e produzem não participa de um lugar qualquer, que também não é um ambiente preparado para sustentar obras de arte. Analisar um espaço em obra nos permite perceber a qualidade específica e contextual que a arte assume quando insere-se no mundo comum, longe dos espaços institucionais. Por isso, é importante analisar a dinâmica de interações que cria com seu ambiente: sua condição de intervenção urbana site-specific.

\section{REFLEXÕES NA CALÇADA: O LUGAR DE UM ESPAÇO}

A cidade é espaço que testa percepções sempre novas sobre a obra, desafiando, muitas vezes, a própria permanência do objeto artístico. A vontade do espaço pode ser mais forte que a da pessoa artista, que precisa dividir intenções com as imposições da urbe e suas imprevisibilidades. Na verdade, é possível ver a cidade ao mesmo tempo como tema, meio e ambientação da obra. Ao mesmo tempo, a obra pode produzir um "olhar crítico sobre a situação urbana", como fala Nelson Brissac Peixoto (1999, p.83), justamente por sua dependência das dinâmicas que habitam o urbano. Essa crítica é produzida justamente pela relação íntima com o espaço que possui a obra, sua "colocação em situação" (PEIXOTO, 1999, p.82) em que é atravessada pelas problemáticas que também se apresentam, direta ou indiretamente, na urbe. Sua existência autônoma e institucionalizada é colocada em xeque. Uma intervenção urbana geralmente produz uma relação crítica com o ambiente : Brian O’Doherty (2002) identifica que as intervenções artísticas tendem a conflitar com o já estabelecido, literalmente intervindo na realidade tal como como ela se apresenta. Nesse diálogo, a impermanência e a efemeridade são um destino previsível, já que, se aspirar à permanência, o caráter de intervenção se esvai. A obra simplesmente não existe mais sozinha, mas se constrói entre dois campos: sua própria realidade e aquela dos seus receptores. $\mathrm{O}$ seu significado se localiza numa "região intermediária (de limites imprecisos) de convergência" (PALLAMIN, 2000, p.61) entre público, obra e rotina urbana, o que pode produzir incompreensões e rejeições. De toda forma, a cidade abarca tais conflitos e pluralidade de percepções, pois é nela que a "a cultura é socialmente situada e especialmente vivida" (PALLAMIN, 2000, p.64). A vivência urbana abarca os paradigmas, mas também as incoerências e os choques que são próprios do cotidiano e das relações sociais tecidas diariamente, e nele a arte habita de forma opositora ou conformadora, mas encontra invariavelmente um espaço propício para sua manifestação. A arte é, como indica Henri Lefebvre (2006, p.41), um "espaço de representação" e, portanto, participa ativamente da produção de um espaço social de forma poética e simbólica, contribuindo para a criação de subjetividades em meio às "representações de espaço" (locais construídos pelas vias e códigos oficiais dos planejadores urbanos). Na obra de Laura Miranda, o espaço poético da obra vive em simbiose com um importante elemento urbanístico da cidade de Curitiba, o "calçadão" da Rua XV de Novembro, a primeira rua fechada para pedestres do Brasil (OLIVEIRA, 2000). Seu público são os típicos transeuntes: o turista que visita a cidade, o comerciante dono de seu negócio entre as esquinas, os consumidores de bens e serviços, o trabalhador que percorre a rua, o jovem voltando da escola. Eles são parte da obra, pois a percorrem e, enquanto o fazem, ativam o seu sentido intrínseco ao espaço.

A lógica da obra de arte site-specific condensa transformações sobre a própria ideia de como um local e seu contexto impactam o significado da obra e suas reverberações (KWON, 2008). A arte cria relações específicas, num diálogo próximo com o que há de mais próprio naquele local. Um lugar possui dimensões históricas, sociais e discursivas específicas que, ao longo de décadas de consideração de como o sentido da obra emerge de seu contexto, ganharam cada vez mais peso no

\footnotetext{
${ }^{5}$ A cristaleria em questão foi a Raiar da Aurora, localizada em Curitiba, que patrocinou a obra da artista. (ESCULTURA Pública, 2012, aos 34 minutos).
} 
processo de criação e fruição artística. Em suas primeiras manifestações ${ }^{6}$, a obra site-specific costumava se apoiar em aspectos formais do local, que emprestava apenas sua físicalidade às dimensões da obra. Essa dependência de um espaço percebido como único também cria um trabalho único, como percebeu James Meyer (2000). Mesmo em forma de intervenção ou crítica, diz o autor, o "o desfecho formal do trabalho é determinado pelo espaço físico", já que a intervenção "se conforma aos limites físicos da situação" (2000, p.24). Para Meyer, esse site-specific físico tem uma certa monumentalidade, a forma de um trabalho designado para aquele local mesmo que procure produzir atritos, o que é reforçado pela necessidade da presença do espectador para conferir sentido à intervenção poética. Até certo nível, essas definições se aplicam também ao trabalho de Laura Miranda, sobretudo em seus aspectos formais: seu trabalho é estático, literalmente cimentado ao chão de um ponto geográfico específico, em diálogo estreito com aquele local. Contudo, vai além. Uma análise mais aproximada desse diálogo e a aferição mais detida de sua materialidade mostram "Ladrilhos" como uma obra que interage com "dimensões institucionais, econômicas e políticas do espaço, enfatizando suas contradições e conflitos" (PEIXOTO, 1999, p.83), enfim, explorando os limites das intervenções urbanas de local específico. De início, a artista trabalhou com a intenção "muito mais de produzir uma experiência estética" do que "instalar uma obra que tivesse uma materialidade ostensiva" (ESCULTURA Pública, 2012, aos 25 minutos), denotando então a vontade de colocar o fluxo de transitoriedades do local em maior relevância do que os dados meramente físicos do sítio. No escopo do Projeto Escultura Pública de 1992, do qual a obra fez parte, não havia a intenção de uma instalação de obras permanentes, mas sim "a ocupação temporária como parte de um debate sobre o espaço urbano e a escultura contemporânea" (BANDEIRA; MIRANDA, 2013, p?). "Ladrilhos", portanto, é a única obra que ainda resiste relativamente em seu espaço de instalação, mas de forma completamente integrada ao espaço, manchando-se e deteriorando-se mais e mais com o passar do tempo e os andares dos passantes, como qualquer calçada de cidade. O relativo desaparecimento da obra através de uma incorporação na paisagem urbana era esperado. Ainda assim, como já mencionado, o diálogo que produz com o espaço ultrapassa limites do site-specific meramente físico e adentra o campo "informacional", indicando uma "corrente de significados e histórias embricadas” (MEYER, 2000, p.25, tradução nossa). Para perceber essa dimensão, é necessário um olhar mais detido para a Rua XV de Novembro e o que ela representa.

\section{UMA INTERVENÇÃO NA RUA XV: OS SENTIDOS DE UM ESPAÇO ESPECÍFICO}

Capítulo marcante na história do urbanismo de Curitiba, que é dirigida a partir do Plano Diretor produzido em meados da década de 1960 e instaurado a partir do primeiro mandato de Jaime Lerner como prefeito, o "calçadão" da Rua XV de Novembro é um marco do caráter pretensamente "humanista" do desenvolvimento urbano da cidade. Entre as décadas de 1960 e 1970, com dois mandatos de Lerner (1971-1975 e 1979-1983) e Saul Raiz (1975-1979) como prefeitos biônicos ${ }^{7}$, a capital paranaense recebia apelidos como "Laboratório de experiências urbanísticas", dada a relevância da pesquisa e aplicação do urbanismo em seu desenvolvimento (OLIVEIRA, 2000, p.15). Em meio aos vários fluxos de velocidade que passaram a cortar a paisagem urbana, graças a valorização da mobilidade como eixo estrutural de desenvolvimento, o que dava a esse plano urbano seu toque modernista, a criação de espaços de socialização na área central da cidade contribuía para o aspecto "humanista" do planejamento. Foi prevista então a criação do centro histórico, acompanhada da pedestrianização de uma parte do centro da cidade. Priorizando os espaços de

\footnotetext{
${ }^{6}$ Kwon (2008, p.166) observa que a partir dos anos 1980 percebe-se a emergência de trabalhos site-specific que compreendem dimensões contextuais para além do meramente formal, incorporando particularidades da vivência nos espaços, entendendo que a realidade de um local específico transborda o material na obra.

${ }^{7}$ Ambos integraram o ARENA, partido alinhado ao governo militar com amplo poder de indicar nomes ao executivo sem qualquer participação popular no processo de escolha. Lerner e Raiz não foram eleitos para os mandatos em questão, mas nomeados pelo regime militar.
} 
circulação desacelerada e de socialização, a Rua XV de Novembro é privada do tráfego de veículos em 1972 como parte do projeto urbanístico. Esse fechamento para carros de um dos mais famosos logradouros da cidade não veio sem críticas, sobretudo dos comerciantes que temiam a queda nos faturamentos. Contudo, num aproveitamento pleno do poder instituído e referendado pela afiliação com o governo da ditadura militar do período, evitando processos judiciais que atrapalhassem seus planos, a prefeitura conseguiu em apenas três dias readequar a rua, transformando três quarteirões em largas calçadas com floreiras (VEJA, 1987). Começava então o "calçadão", que na década de 1990 já se estendia da Praça Santos Andrade até a Praça General Osório, no centro da cidade, em uma área própria para pedestres e comércio. Desde então, a Rua tornou-se um marco simbólico na paisagem urbana, sendo tanto um elemento rotineiro para os habitantes quanto relevante para o turismo urbanístico. É marcante que não se trata apenas de um espaço de lazer, mas sobretudo funcional: abriga um fluxo intenso de pedestres que, por sua vez, transformam-se em consumidores das lojas nos arredores, sem falar nos trabalhadores da região. A estetização dos elementos urbanos funcionais é, como observa Fernanda Sánchez García (200?, p.2), uma característica do projeto de urbanização iniciado em Curitiba nos anos 1970. A rotina de circular no "calçadão", aproveitar o centro pedestrianizado e as outras soluções urbanas são atitudes constitutivas de um tipo de "cidadão exemplar" buscado por esse urbanismo "humanista". A infraestrutura não é apenas elemento figurante na rotina do habitante, mas é algo que determina o tipo de ser que ele é perante o coletivo. Ao longo do terceiro mandato de Jaime Lerner (1989-1992) à frente da prefeitura de Curitiba (durante o qual foi realizado o Projeto Escultura Pública) a cidade colhia frutos da imagem positiva projetada a partir das soluções de planejamento urbano. "Cidade planejada", "cidade da qualidade de vida", "capital ecológica" e "cidade de primeiro mundo" eram alguns dos títulos publicizados na mídia e reconhecidos entre habitantes de outras capitais (GARCÍA, 200?, p.5). Com o sucesso reconhecido no setor do planejamento urbano, as investidas do prefeito foram sobretudo de ordem estética, garantindo um maior lastro midiático para lançar a cidade entre outras capitais mundiais e gerar competitividade na atração de investimentos no cenário internacional (OLIVEIRA, 2000).

$\mathrm{Na}$ reflexão acerca do turismo urbanístico verifica-se a valorização extrema da imagem da cidade dentro do projeto modernizador - com incidência marcante não apenas na materialidade urbana mas também na vida coletiva, comportamentos e apropriação dos lugares. (GARCÍA, 200?, p.7).

Para Fernanda Ester Sánchez García, o resultado de décadas de investimento no planejamento urbano ultrapassou a intervenção na materialidade da cidade e produziu uma imagem própria de sucesso. Imagem esta que representava não apenas uma cidade funcional, mas também um urbanismo responsável por soluções que afetavam a vida profundamente. Retomando novamente "Ladrilhos", vemos que o conceito de functional site de James Meyer torna-se pertinente, uma vez que ele nos ajuda a entender obras como a Laura Miranda, que interpretam o espaço mais como um conjunto imbricado de informações e ações históricas do que como um ponto físico inerte e específico. Por outras palavras, "Ladrilhos" até pode ser um local temporário, conectado a um sítio específico ou não, mas “certamente não privilegia este local" (MEYER, 2000, p.25, tradução nossa). A obra não é presa às coisas físicas do local específico, mas se apega em características subjetivas, em alegorias referentes aos laços produzidos entre espaço e os corpos que ali habitam, as forças, intenções e agentes que ali estão. Se trata, então, de perceber, selecionar e manejar tudo o que atravessa aquele espaço e o constitui, como um "mapeamento de filiações institucionais e textuais e os corpos que se movem entre eles (do artista acima de todos) (...) é um sítio informacional, um palimpsesto de textos, fotografias, gravações em vídeo, espaços físicos e coisas (...)" (MEYER, 2000, p.25, tradução nossa). A esse ponto, percebe-se que não se trata de um local nem obra fixos e facilmente delineáveis, mas de referências cambiantes que não almejam a produções permanentes. Autoria, permanência e estabilidade são questões secundárias ou retrabalhadas no site funcional. Em 
relação à obra de Laura Miranda, as proximidades com o conceito aparecem sobretudo na interação do espaço calçadão e seus transeuntes. Uma análise neste sentido faz surgir perguntas: o que é mais relevante à obra quando considera-se seu local de instalação? Aquele local específico era necessário? O mais relevante foi a materialidade ou o diálogo com o histórico daquele ambiente? Fatores como imprevisibilidade, impermanência, o atravessamento de forças e intenções múltiplas do cotidiano e a conversa com elementos culturais e sociais (sobretudo a política de urbanismo) que extrapolam o alcance da obra e da artista parecem estar presente em todos os momentos da obra. Também são visíveis até hoje. Vale dizer, contudo, que para Meyer o functional site também extrapola características como aquelas percebidas na obra analisada aqui, compreendendo igualmente obras móveis de "artistas nômades" (MEYER, 2000, p.28, tradução nossa), que adaptam seus trabalhos materialmente aos diferentes sítios de instalação, mantendo certa coerência poética que consegue habitar múltiplos espaços.

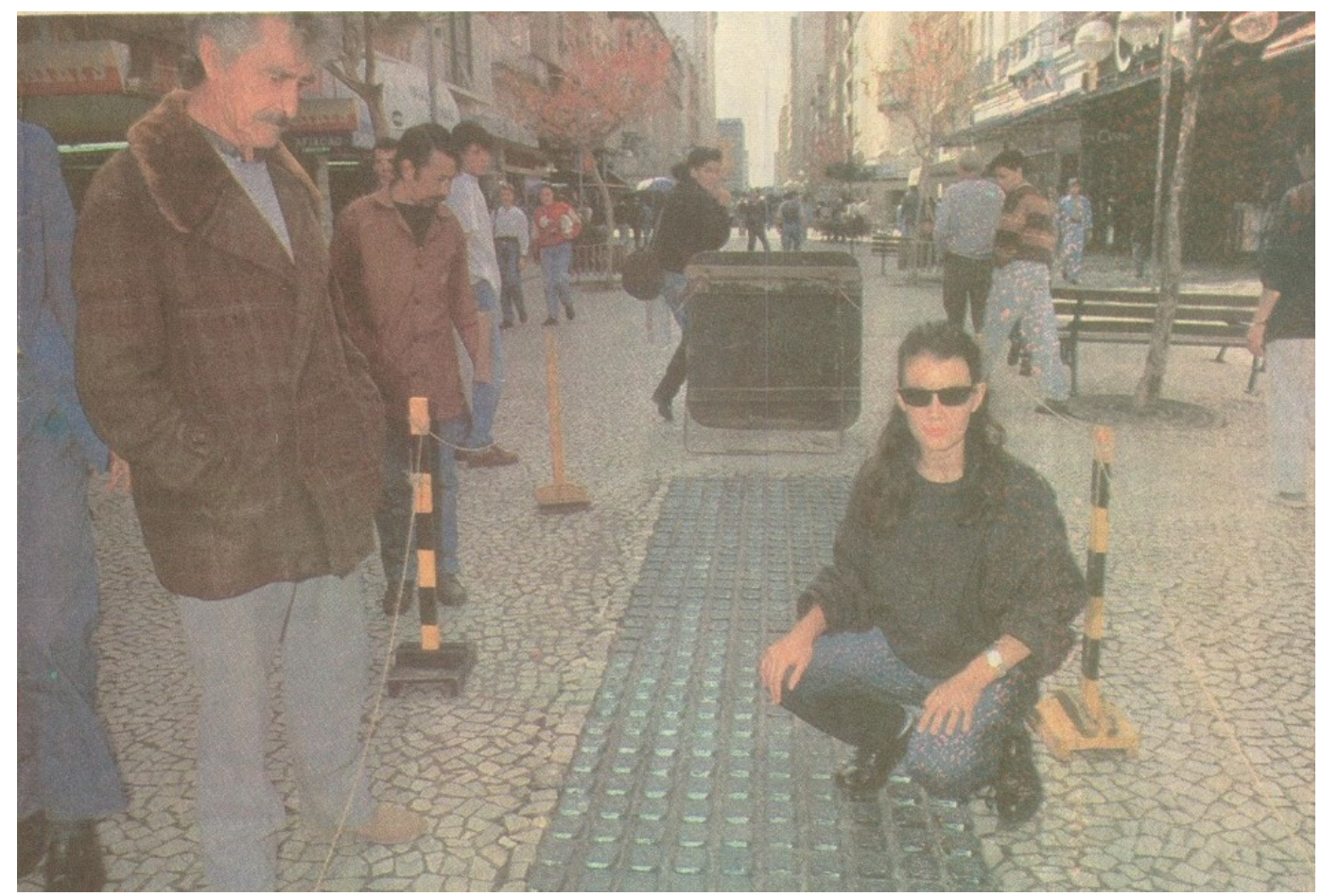

Figura 3. A artista Laura Miranda e sua obra em 1992. Foto: Maurilio Chelli. Fonte: Jornal O Estado do Paraná, 17 de Maio de 1992.

\section{EM CONCLUSÃO}

A obra de Laura Miranda, como as outras do Projeto Escultura Pública, podem ser vistas no sentido de uma crítica à estetização dos espaços e constantes modificações na paisagem urbana impostas pelo poder público local. Entendendo a artista como parte de um coletivo, é válido analisar suas intenções em relação às ações do Projeto. Sendo assim, vê-se que o espaço aberto pelas obras e seu debate quis provocar uma nova compreensão da estética e vivência na cidade. Entrevistas e comentários feitos vinte anos após o evento indicam a percepção de alguns participantes sobre como estes percebiam as transformações urbanísticas em Curitiba e seus agentes, e o lugar da arte nesse processo perceptivo. Yiftah Peled, por exemplo, considerava àquela época que os "espaços públicos urbanos estavam sendo utilizados indevidamente e de maneira pouco democrática por um político" (PELED, 2013, p?), e viu na arte pública uma forma de protesto. Já Eliane Prolik criticou a presença na cidade das estações-tubo, solução do transporte urbano iniciada em 1991 que estaria "descaracterizando" lugares históricos da cidade (ESCULTURA Pública, 2012, aos 38 minutos). 
Para Marco Mello, articulador do projeto, as transformações correntes nas estruturas viárias da capital, das vias públicas aos ônibus e terminais, produziram uma "aceleração" do cotidiano que "levava ao apagamento da própria vida.". Ele acreditava que as ações e elementos do Escultura Pública, quando inseridas no "corpo social", pudessem "criar uma nova forma de experiência, entre os sujeitos e a própria vida (...) que não fosse simplesmente um elemento que remetesse à circulação" (ESCULTURA Pública, 2012, aos 14 minutos). Essas percepções críticas expõem graus da discordância dos participantes em relação às mudanças na paisagem da cidade, indicando que o planejamento urbano em Curitiba não foi participativo. Não são observadas apenas algumas ações pontuais sobre o espaço urbano, mas um conjunto de atitudes que, na visão do Projeto, modificaram o cotidiano dos espaços sociais, sobretudo visualmente. O poder público, personificado na figura do prefeito, ocupa um papel central nesse debate. Para André de Souza Carvalho (2013), de fato, as últimas décadas do planejamento urbano curitibano, desde a implantação do seu plano diretor, produziu afinidades entre as instituições municipais, o marketing urbano e a elite econômica local, criando vínculos "fortes e coesos, impedindo outra forma de articulação ou apreensão do planejamento, como o participativo" (ESCULTURA Pública, 2012, aos 18 minutos). De toda forma, embora o Projeto Escultura Pública tenha contado com algum auxílio financeiro vindo do poder municipal ${ }^{8}$, além de outros patrocínios estratégicos buscados pelos participantes, o fato é que a produção do evento realizou-se sobretudo a partir de ações pessoais de cunho voluntário.

De maneira geral, a crítica mais evidente e apreensível produzida pelas esculturas públicas como a de Laura Miranda e seus colegas parece ocorrer em nível visual. Como observa a jornalista Adélia Maria Lopes, em 1992, as obras produzidas no escopo do projeto produziram um "contraponto com as estátuas equestres e bustos de nossas praças" (LOPES, 1992, p?). "Ladrilhos" se destaca de maneira diferenciada, sendo uma intervenção sutil, mas com força suficiente para alterar minimamente o cartão-postal de uma grande cidade. A obra teve sucesso em se fazer parte da paisagem urbana, em não apenas interferir neste espaço a partir de suas características contingenciais, mas em ser absorvido por ele e seu fluxo. Seguindo a intenção da artista, a obra não tem uma visualidade ostensiva, mas é clara o suficiente para produzir um ruído, um intervalo na conformidade visual que aquele local oferece. O famoso "calçadão" da Rua XV de Novembro, símbolo de um projeto urbanístico ímpar, é colocado em suspensão, porque atravessado por uma crítica disruptiva relativa ao domínio do espaço institucionalmente exercido pelos administradores urbanistas. É um registro, um fragmento de uma visualidade particular em meio à conformação de visão dominante sobre a cidade. Como comenta a artista: "A questão era naquele momento (...) O tempo, a passagem das pessoas (...) $\mathrm{O}$ caminhar (...) $\mathrm{O}$ vidro fosse sendo riscado e que se apagasse mesmo, e se integrasse ao piso, ao petit-pavê, à calçada e que virasse calçada." (ESCULTURA Pública, 2012, aos 89 minutos). Para ela, então, a arte é veículo de diálogo com a cidade e suas forças em transformação. A sutileza de sua crítica reside na própria impossibilidade de produzir uma condição diferente naquele espaço. Laura Miranda conseguiu produzir um território de contato com o público que, enquanto oferece uma experiência única, se conforma e participa da padronização do espaço e seus fluxos. Qualidade notória de sua obra não é sua oposição ostensiva ao espaço, mas sim a capacidade de mascarar-se no comum e aguardar ser percebida, pacientemente.

8 Segundo o galerista Marco A. Silveira Mello, a prefeitura teria financiado uma pequena porcentagem do orçamento das obras e pago passagens e estadias para os palestrantes convidados do evento $1^{\circ}$ Fórum da Escultura Pública (ESCULTURA Pública, 2012. Aos 70 minutos). 


\section{REFERÊNCIAS}

ARAÚJO, Adalice. Revolucionário projeto de escultura pública desafia a crise. Cultura G: Artes Visuais, Gazeta do Povo. Curitiba, 10 de maio de 1992.

ARCHER, Michael. Arte contemporânea: uma história concisa. São Paulo: Martins Fontes, 2012.

BANDEIRA, Denise; GUIMARÃES, Rossana; MELLO, Marco A. Silveira; MIRANDA, Laura; PELLED, Iftah; PROLIK, Eliane; ZUGMAN, David. Carta ao Prefeito Municipal de Curitiba Sr. Rafael Greca de Macedo. Curitiba, 8 de fevereiro de 1993.

BANDEIRA, Denise; GUIMARÃES, Rossana; MIRANDA, Laura; PELED, Yiftah; PROLIK, Eliane; ZUGMAN, David. Projeto Escultura Pública. Curitiba, arquivos de Laura Miranda, março de 1992.

BLOOMFIELD, Tania. O espaço urbano vivido, percorrido e produzido por práticas artísticas contemporâneas, na cidade de Curitiba. Tese (Doutorado em Geografia). Universidade Federal do Paraná, Curitiba, 2012.

CARVALHO, André de Souza. Urbanismo em Curitiba: mudanças e transformações no pensar a cidade. In: XV ENCONTRO NACIONAL DA ASSOCIAÇÃO NACIONAL DE PÓSGRADUAÇÃO E PESQUISA EM PLANEJAMENTO URBANO E REGIONAL (ENANPUR), $n$. $1,2013$.

CURITIBA: a cidade-modelo de um país viável. Revista Veja. edição 1281, ano 26, n.13, 31 de março 1993.

ESCULTURA Pública, 1992. Mesa-redonda. Direção de Luís C. dos Santos; Tânia Bloomfield. Curitiba, PR: Projetos de extensão Arte em Vídeo na UFPR e O Artista na UFPR - UFPR, 2012. 1 DVD (124 m), color.

FOSTER. Hal. O complexo arte-arquitetura. São Paulo: Cosac Naify, 2015.

GARCÍA, Fernanda Ester Sánchez. A cidade reinventada: o papel do turismo urbanístico em Curitiba.

Disponível

em:

$<$ http://www.observatoriogeograficoamericalatina.org.mx/egal6/Geografiasocioeconomica/Geogra fiaturistica/834.pdf> Acesso em: 26 maio 2021.

JUDD, Donald. Objetos específicos. In: COTRIM, Cecília; FERREIRA, Glória (org.). Escritos de artistas - anos 60/70. São Paulo: Zahar, 2006. p. 96-106.

KRAUSS, Rosalind. A escultura no campo ampliado. Arte \& Ensaios, Rio de Janeiro, n. 38, p. 128$137,2008$.

KWON, Miwon. Um lugar após o outro: anotações sobre site-specificity. Arte \& Ensaios, Rio de Janeiro, n. 17, p. 167-187, 2008.

LEFEBVRE, Henri. A produção do espaço. Trad. Doralice Barros Pereira e Sérgio Martins (do original: La production de l'espace. 4 e éd. Paris: Éditions Anthropos, 2000), 2006.

LOPES, Adélia Maria. Esculturas florescem no traçado urbano. Almanaque, Estado do Paraná. Curitiba, 20 de maio de 1992.

MEYER, James. The functional site or the transformation of site-specificity. In: SUDERBURG, Erika. Space, site, intervention: situating installation art. Minneapolis Minessota: University of Minnesota Press, 2000, p. 12-32.

MIRANDA, Laura; BANDEIRA, Denise. Entrevista com Denise Bandeira e Laura Miranda, 30 de Setembro de 2013. Entrevista para Cleverson Sgoda.

MORRIS, Robert. Tamanho é documento. ARS, São Paulo, n. 31, p. 209-225, 2017. 
O’DOHERTY, Brian. No interior do cubo-branco. São Paulo: Martins Fontes, 2002.

OLIVEIRA, Dennison de. Curitiba e o mito da cidade modelo. Curitiba: Ed. da UFPR, 2000.

PALlAMIN, Vera Maria. Arte urbana; São Paulo: região central (1945 - 1998): obras de caráter temporário e permanente. São Paulo: Fapesp, 2000.

PEIXOTO, Nelson Brissac. Intervenções urbanas. Rua, Campinas, p. 81-88, 1999.

Mania Nacional: O calçadão de Curitiba é imitado em todo o país. Revista Veja. 10 de junho de 1987.

PELED, Yiftah. Entrevista com Yiftah Peled. 24 de Outubro de 2013. Entrevista por Cleverson Sgoda. 